\title{
REALIDADE E FICÇÃO EM ELEANOR MARX: FILHA DE KARL; UM ROMANCE
}

\author{
REALITY AND FICTION IN ELEANOR MARX: FILHA DE KARL; UM ROMANCE
}

\author{
Lidiane Pereira Coelho ${ }^{1}$ \\ João Batista Cardoso ${ }^{2}$
}

\begin{abstract}
Resumo: $\mathrm{O}$ artigo ora apresentado analisa o modo como alguns aspectos da realidade se tornam presentes na obra de ficção. Para tanto utiliza, como corpus, o romance Eleanor Marx, filha de Karl; um romance, de Maria José Silveira, que conta a história de Eleanor Marx, filha de Karl Marx, pensador e idealizador do Socialismo. Ativista política e seguidora do Socialismo, Eleanor foi uma mulher à frente de seu tempo, ela abraçou as grandes causas de sua época. A obra, além de recontar, de forma romanceada, os últimos dez meses de vida da personagem, também retrata alguns dos grandes acontecimentos sociais pelos quais passou a sociedade inglesa do século XIX. Nesse sentido, o estudo se propõe a analisar como realidade, ficção e História se imbricam num texto literário, fazendo com que a Literatura se constitua também como construção de conhecimento.
\end{abstract}

Palavras-Chave: Realidade; Ficção; Literatura.

\begin{abstract}
The paper presented here examines how some aspects of reality become fiction in the text. For both uses, such as corpus, the novel Eleanor Marx, daughter of Karl, a novel, Maria Jose Silveira, who tells the story of Eleanor Marx, daughter of Karl Marx, philosopher and founder of Socialism. Political activist and follower of Socialism, Eleanor was a woman ahead of her time, she embraced the great causes of his time. The text, as well as retelling, so novel, the last ten months of life of the character also portrays some of the great social events through which passed the English society of the nineteenth century. In this sense, the study aims to analyze as reality, fiction and history intertwine in a literary text, making the literature also as to constitute knowledge construction.
\end{abstract}

Keywords: Reality; Fiction; Literature.

\section{Introdução}

\footnotetext{
${ }^{1}$ Mestranda em Estudos da Linguagem, pelo Programa de Pós-Graduação em Estudos da Linguagem, do Departamento de Letras, da Universidade Federal de Goiás, Campus Catalão. E-mail: lidia14@ibest.com.br 2 Doutor em Literatura Brasileira (UnB), Pós-Doutorado: "história e hibridismo cultural na ficção latinoamericana" (UFMG). Professor Associado na Universidade Federal de Goiás, Campus Catalão, docência no Programa de Mestrado em Estudos da Linguagem. E-mail: ibccard@gmail.com
} 


\begin{abstract}
A literatura continua sendo uma das manifestações culturais mais importantes de um povo. Nela o homem reflete sua imagem, espelha as contradições e as ambigüidades que definem o ser humano de cada época e sociedade (ZINANI, 2010, p. 13).
\end{abstract}

Ao longo da História da Literatura, diversas obras literárias estabeleceram interfaces entre ficção e realidade. Dessa forma, as características de uma personagem, a trama envolvente ou a descrição artística de fatos históricos, muitas vezes suscitam uma forte relação com o público, fazendo com que, em algum momento, haja o questionamento se o que é narrado no texto é ficção ou um retrato da realidade.

Conforme Candido (2008), antes, exprimir a realidade era uma característica exigida em uma obra pela crítica literária. Hoje, no entanto, conforme o autor, a obra deve ser analisada a partir da confluência entre texto e contexto, sendo que o social é um elemento fundamental na constituição da mesma, entretanto, a obra não é mais vista como a representação fiel da realidade. Corroborando com esta assertiva, Bakhtin (1998) esclarece que a realidade preexiste ao ato da escritura, inserindo-se, portanto, na obra enquanto objeto estético, tornando-se um dos elementos constitutivos da arte literária. Nesse sentido, a realidade não pode ser considerada como único elemento no processo de constituição de uma obra, afinal, ela está presente de alguma forma na trama ficcional, mas esta não é construída a partir exclusivamente de um fato histórico da realidade. Para Bakhtin (1998, p. 360-361) não se pode, portanto,

[...] confundir, como se fez e até hoje ainda se faz, o mundo representado com o mundo representante (realismo ingênuo), o autor-criador da obra com o autor-indivíduo (biografismo ingênuo), o ouvinte-leitor de diversas (e muitas) épocas, que reconstitui e renova, com o ouvinte-leitor passivo seu contemporâneo (dogmatismo de concepção e de avaliação).

Observamos, assim, que o mundo representado interage com o mundo real, mas não significa sua cópia fiel.

A obra de Maria José Silveira (2002) Eleanor Marx, filha de Karl; um romance reflete a história da criação e difusão do Socialismo pelo mundo no século XIX e a vida de Eleanor Marx, uma das personalidades históricas marcantes nesse período. A escritora, por meio dos diálogos de Eleanor, descreve os acontecimentos registrados historicamente, explicando fatos relativos à implantação do Socialismo na Inglaterra e no 
mundo, referindo-se aos movimentos operários, às greves, à política, à desigualdade social, à discriminação contra as mulheres. Além disso, Eleanor redige cartas ao longo do romance para Olive Schreiner e Freddy (Henry Frederik Demuth) falando sobre suas mazelas pessoais e sobre seu casamento, e para os camaradas políticos discutindo sobre política. Para (re)contar os fatos históricos, a personagem se utiliza da memória para proceder à reatualização e à reanimação do passado por meio de suas enunciações, dos fluxos de consciência e das cartas que escreve. Assim, a concepção de memória tornase, neste contexto, importante para a compreensão dos fatos históricos e da construção literária, na medida em que a entendemos como uma reatualização de acontecimentos (históricos, discursivos, individuais/pessoais) passados, que são reanimados em situações no presente.

Em Eleanor Marx, filha de Karl; um romance, a autora mostra, por meio da ficção, e utilizando da metaficção historiográfica, a história de amor vivida pela filha de Karl Marx e sua trajetória de vida e, com isso, apontou alguns dos grandes acontecimentos sociais e políticos marcantes da época em que aconteceu o romance e também da juventude de Eleanor. Segundo Linda Hutcheon (1991), "a metaficção historiográfica é entendida enquanto uma tendência à composição literária ligada à História. Utilizando elementos da História, esse tipo de romance visa a uma reinterpretação do passado, bem como a uma reflexão sobre a literatura. Ela rejeita a construção mimética dos acontecimentos".

Diante do exposto, a proposta deste artigo é discutir a relação entre realidade, ficção e história na Literatura e analisar como esses três elementos convivem na obra Eleanor Marx, filha de Karl; um romance.

Ressaltamos que não temos a pretensão de esgotar o assunto, haja vista a complexidade desta discussão e as inúmeras possibilidades de outros olhares sobre o corpus.

\section{Ficção e realidade na obra literária}

As fronteiras entre realidade e ficção na obra literária, muitas vezes, são bastante tênues, haja vista que há obras ficcionais que retratam lutas, sonhos, medos, angústias, realizações, esperanças, fantasias, injustiças, enfim, uma gama de sentimentos, valores, atitudes, pensamentos que são comuns na vida cotidiana. No entanto, a obra literária, 
enquanto objeto estético, não retrata a realidade fidedigna, pois se assim fosse, ela se reduziria a um reprodutor mecânico da realidade, que captaria e transmitiria fielmente os acontecimentos da vida real.

Mas é comum nos questionarmos a respeito da linha limítrofe que existe entre o que é ficção e o que é realidade em uma obra literária que traz em seu bojo acontecimentos históricos oficiais, isto é, sobre a realidade inserida na ficção e vice versa.

Segundo Candido (2007, p. 71), a obra literária usa fatos e/ou personagens históricos em sua ficção, no entanto, essas personagens são "construídas a partir de um modelo real, conhecido pelo escritor, que serve de eixo ou ponto de partida. $O$ trabalho criador desfigura o modelo, que todavia se pode identificar". Nesse sentido, entendemos que a realidade é constitutiva da obra de ficção, é um de seus elementos fundamentais, entretanto, o autor lança um olhar sobre esta realidade, desfigurando-a e criando uma nova realidade, a realidade da obra ficcional.

Dessa forma, o autor tem a possibilidade de mostrar artisticamente aspectos da realidade em suas obras ficcionais, sem o compromisso que o historiador tem de retratar impessoalmente os fatos e sem que a obra perca seu caráter de ficcionalidade. A despeito dessas considerações, entendemos que a impessoalidade do historiador não é absoluta, pois este constrói sua historiografia a partir de acrescentamentos e supressões, bem como escolhe um modo linguístico de prefiguração do campo que é determinante na escolha do enredo que pode ser, nas palavras de White (1995), estória romanesca, tragédia, comédia ou sátira. A propósito, segundo Borges (1993, p. 41),

Através das histórias contadas por literatos podemos elucidar aspectos relacionados à cultura e à sociedade de um povo. Contudo, não podemos ter, nunca, a ilusão do documento transparente, expressão cristalina da realidade que se apreende, mesmo considerando o literato informante preocupado e exigente.

Em outras palavras, existe uma relação estreita entre realidade e ficção numa obra literária. De fato, podemos encontrar os valores de um povo, sua cultura, suas lutas, seus ideais, suas conquistas, sua política assim como a sensibilidade de uma época em uma obra literária.

A literatura pode se apoderar de qualquer tema e transformá-lo em ficção. Ela mostra aspectos da realidade de outro modo, de uma forma artisticamente elaborada, sem que seja necessário o atendimento à convenção de veracidade, pois seu objetivo não 
é discutir verdades, apontar caminhos, difundir valores ou discutir o caráter das pessoas, ao contrário, a literatura tem como objetivo entreter, produzir conhecimentos, causar prazer. Consoante com esta concepção, Barthes (1977) ressalta que a literatura assume muitos saberes, pois uma obra literária é atravessada por conhecimentos da ordem do histórico, do geográfico, do social, do político, do linguístico. Podemos dizer então que esses conhecimentos estão todos presentes na obra literária, mas não são fixados por ela. A obra literária não discute esses saberes, não os revela, apenas os traz imbuídos, sugeridos, em sua trama ficcional.

O imbricamento entre realidade e ficção torna a obra literária mais próxima do contexto sócio-histórico, político e cultural do leitor, e esse fato pode fazer com que o mesmo desperte um maior interesse pela leitura e exerça uma reflexão a respeito de temas representativos de nossa situação histórico-social. Não estamos afirmando aqui que a literatura deva tratar exclusivamente de assuntos engajados nas questões sociais, ao contrário, o engajamento social é parte integrante de sua construção. De acordo com Candido (2007), a literatura tem responsabilidade na construção de uma cultura. Dessa forma, ela se torna um dos instrumentos para se pensar as questões sociais que são constitutivas da construção cultural e política de um povo.

\section{O imbricamento entre História e ficção na trama literária}

Um observador menos atento pode entender que História e ficção são duas formas de narrativa que não mantêm entre si nenhuma relação aparente. Neste artigo, optamos por grafar o termo História com inicial maiúscula para nos remetermos aos fatos ocorridos na vida dos povos e para diferenciar da acepção de enredo (SANTOS, 1996). Desta feita, enquanto a História é objetiva, detém-se no estudo de acontecimentos do passado e tem como função formar e informar, a obra ficcional é subjetiva, seu compromisso é com o estético, com o prazer e o entretenimento. Segundo Cardoso (2009, p. 21), "A realidade social é a fonte onde a literatura e a história buscam seu alimento mútuo e se condicionam. A objetivação da história se dá por meio da concretude da vida que analisa, conceitua e transporta para o texto historiográfico. A literatura, ao contrário, privilegia a subjetividade e o mito." 
Dessa forma, a realidade social é o alimento tanto da História quanto da literatura, porém, a História analisa essa mesma realidade de modo objetivo, já a literatura, cujo ponto de atração é a ficção, a vê por meio da subjetividade. Entretanto, apesar dessa aparente disparidade, cada um dos observadores (o literato e o historiador) capta muito mais do que uma situação real passível de ser reproduzida e a transforma em sua obra prima.

Isso ocorre porque entendemos que, na obra ficcional, o leitor se identifica ou se desidentifica com as personagens e deixa fluir suas emoções e sentimentos com relação ao que está lendo. Na História, estudamos nomes, datas e acontecimentos que, muitas vezes, estão distantes de nossa realidade social imediata. Daí talvez o nosso interesse, enquanto leitores, ser maior por obras de cunho ficcional, pois, ao passo que a obra literária ficcional não narra fatos ocorridos, mas a representação de um acontecimento ou do que poderia vir a acontecer, a História se baseia em fatos reais e se origina de pesquisas acadêmico-científicas. Apesar dessa aparente diferença, as duas são constituídas pela narração. São maneiras diferentes de cada um dizer a sua verdade, como explica Albuquerque Júnior (2006, p. 63), quando afirma que

A interpretação em História é a imaginação de uma intriga, de um enredo para os fragmentos de passado que se têm na mão. Esta intriga para ser narrada requer o uso de recursos literários como as metáforas, as alegorias, os diálogos etc. Embora a narrativa histórica não possa ter jamais a liberdade de criação de uma narrativa ficcional, ela nunca poderá se distanciar do fato de que é narrativa, e, portanto, guarda uma relação de proximidade com o fazer artístico, quando recorta seus objetos e constrói, em torno deles, uma intriga.

Em algum momento da escritura de sua trama, a obra literária ficcional encontra-se e se entrelaça com a História. Nesse entrelaçamento, podemos observar que a obra literária ficcional dá voz às personagens principais, mas também o faz com outras personagens (secundárias, terciárias etc.). Nesse aspecto, a "nova história" se assemelha a ela a partir do momento em que procura dar voz aos inúmeros atores sociais que participaram dos fatos históricos oficiais, mas que são deixados à margem pela História tradicional. Podemos constatar também que a obra ficcional pode trazer o relato de acontecimentos históricos imbuídos em sua trama textual.

Afrânio Coutinho (2007) afirma que "a análise exata (close analysis) da obra de arte como tal e na sua totalidade e unidade não exclui o conhecimento de certos fatos 
relevantes que a integram na história da civilização." Nesse sentido, o autor reconhece a relevância dos elementos históricos, como a economia, a política, a moral, a religiosidade, entre outros, na constituição da obra ficcional.

Ao longo dos anos, autores de obras literárias têm se utilizado de fatos e acontecimentos históricos na composição de sua obra ficcional. Isso nos possibilita lançar outro olhar sobre os fatos históricos oficiais, observando-os por outra ótica, analisando-os a partir de outro lugar, o lugar da subjetividade. Entre esses autores, destaca-se Maria José Silveira, que escreveu, entre outras obras, O fantasma de Luis Buñuel e Eleanor Marx, filha de Karl; um romance. O primeiro conta a história de um grupo de amigos que viveu os anos negros da ditadura militar no Brasil e o segundo narra a história de Eleanor Marx, a filha caçula de Karl Marx.

Na segunda obra referida, o leitor reúne as informações esparsas ao longo do texto e relê a história sobre a implantação do Socialismo na Inglaterra e no mundo, a partir da perspectiva de Eleanor, cujo drama pessoal se dilui nessa história. Nesse sentido, a obra revela outras possibilidades de apreensão e compreensão dos fatos históricos.

A autora mostra, em seu romance, como poderiam ter sido os últimos dez meses de vida de Eleanor Marx, suas lutas, seus ideais, seus sonhos, sua personalidade forte e marcante de militante política e também nos oferece uma releitura de como era a sociedade inglesa no século XIX. O livro se baseia em fatos relatados nas várias biografias de Marx e de sua filha Eleanor, sobretudo, na abrangente biografia Eleanor Marx, escrita por Yvonne Kapp. Por meio do romance, Maria José Silveira nos conta também fatos da vida de Karl Marx e Friedrich Engels, pensadores do Socialismo, retrata uma sociedade marcada pela desigualdade social, revela uma Eleanor engajada politicamente e atordoada por um amor impossível. No entanto, a forma como narra esses fatos, como os ordena, a linguagem que utiliza fazem do romance uma obra ficcional que poderia, quiçá, ser visto na perspectiva do romance histórico.

Portanto, apesar de se tratar de uma obra de ficção, elementos da História estão presentes em praticamente todo o romance, possibilitando-nos observar os fatos históricos por outro viés e por outro olhar, o olhar da personagem Eleanor. Segundo Candido (2007, p. 55),

A personagem é um ser fictício, é algo que sendo uma criação da fantasia, comunica a impressão da mais lídima verdade existencial. Podemos dizer, 
portanto, que o romance se baseia, antes de mais nada, num certo tipo de relação entre o ser vivo e o ser fictício, manifestada através da personagem, que é a concretização deste.

Percebemos, então, que, na obra em estudo, há uma estreita relação entre a personagem e a pessoa real, Eleanor, dando-nos a impressão de legitimidade, de autenticidade, por meio da verossimilhança. Apesar de Eleanor Marx ser uma personalidade real, que viveu no século XIX e teve papel importante na história mundial, a trama textual formula-se de tal maneira que ela é tratada como uma personagem fictícia. A autora utilizou-se, enfim, de dados da História e de personalidades históricas para recontar a vida de Eleanor Marx, num romance que integra realidade e ficção, fato e fantasia, reunindo na mesma obra elementos da História e drama pessoal.

\section{Obra literária ficcional e história: uma relação de aproximação em Eleanor Marx, filha de Karl; um romance}

Em Eleanor Marx, filha de Karl; um romance observamos quão possível é trazer para o debate os momentos de encontro entre História e esta obra de ficção, analisando-se as possibilidades de leitura dos fatos históricos ligados à implantação do Socialismo na Inglaterra e no mundo, no século XIX e da vida de Eleanor, uma vez que a referida obra se inscreve em um espaço sócio-histórico e político em que as personagens ficcionais são marcadas pelas relações históricas, sociais e ideológicas do período.

A personagem central desempenhou um papel de destaque no movimento da classe operária inglesa. Nascida em Londres, em 16 de janeiro de 1855, cresceu com O capital, em uma família bastante unida. Era uma intelectual de vanguarda, engajada politicamente, determinada, bem educada, ativista política e sindical, defensora dos direitos femininos e do amor livre na sociedade vitoriana, militante da causa proletária e do movimento proletário internacional; além disso, foi secretária particular do pai e participante ativa na elaboração e implantação das ideias socialistas na Inglaterra e no mundo. Eleanor foi um dos membros fundadores da Federação Social Democrata, autora marxista de livros e artigos e tradutora de obras importantes, como Madame Bovary, por exemplo.

Maria José Silveira mostrou como foram os dez últimos meses de vida de Eleanor Marx. Para tanto, recorreu à Literatura, criando uma obra ficcional, entremeada pelos 
fatos históricos que ocorreram naquele momento, no qual a personagem se insere. $\mathrm{O}$ intuito da autora não foi mostrar os fatos históricos objetivamente, como o faz a história, mas possibilitar aos leitores outra forma de ler esses acontecimentos. Para isso, ela se utiliza do recurso da metaficção historiográfica. Segundo Hutcheon (1991, p. 81), "o que a metaficção historiográfica faz explicitamente é lançar dúvida sobre a própria possibilidade de qualquer sólida 'garantia de sentido', qualquer que seja sua localização no discurso." Assim, ao tratar a questão do Socialismo e da luta pelos direitos humanos, na sociedade inglesa do século XIX, Maria José Silveira mescla ficção, História e realidade, procurando mostrar que não há um sentido único para os acontecimentos históricos, eles podem ser analisados sob outra(s) ótica(s).

Normalmente, o autor historiográfico mantém distância do objeto representado; para ele, os atores dos eventos históricos diluem-se na crônica dos acontecimentos. Dessa forma, salvo as historiografias com enredo de estória romanesca como as de Michelet e Carlyle, o movem os eventos não são as figuras, mas os acontecimentos. $O$ autor de obras literárias, ao contrário, mesmo os realistas mais puros têm os olhos voltados para o homem e é para este, não para o Estado que produz seu texto. No caso da obra em tela, o relato das lutas pelos direitos humanos toma forma e ganha vida nas ações de Eleanor Marx; seu drama pessoal misturou-se nessa luta, que culminou por se tornar um e somente um destino. O conflito para o personagem do romance coloca-se em seu horizonte e o resultado da luta é que determinará as formas de sua existência. Eleanor Marx é uma pessoa com cadastro na crônica dos acontecimentos históricos, o mesmo se diz da luta pelos direitos humanos. Entretanto, o fato mais pungente da sua vida, o suicídio, deu-se tendo como causa imediata a desilusão amorosa, mas remotamente remete a sua luta inglória contra a classe que guarda os privilégios.

Quando a personagem Eleanor fala do Capitalismo, afirma que "Os capitalistas aboliram a 'propriedade privada' das classes trabalhadoras, e nós pretendemos que ela Ihes seja devolvida. Todos os homens, então, terão o direito à propriedade privada, pois todos os homens pertencerão a uma só classe - a classe dos produtores" (SILVEIRA, 2002, p. 72). Observa-se aqui a luta revolucionária dos marxistas pela igualdade social. Todos os homens devem ter os mesmos direitos e pertencerem a uma só classe. A estratificação social deveria ser abolida. Nesse ponto, encontramos os traços da História oficial registrando que, para os marxistas, a emergência das relações de produção com 
base nos preceitos socialistas exige a dissolução do capitalismo e a consequente socialização "dos meios de produção à escala de toda a sociedade, e isto só é possível mediante a conquista do poder político, criando-se pela primeira vez um sistema econômico mundial da revolução e da construção consciente e planejada da nova sociedade" (KONSTANTINOV, 1982, p. 62).

Segundo a História, os marxistas, e aqui incluímos Eleanor Marx, defendem a socialização dos meios de produção, ou seja, que toda a sociedade tivesse acesso a eles. Para isso, a classe operária deveria conquistar o poder político, econômico e social, de forma que a sociedade pudesse se reestruturar isenta das desigualdades sociais que afligem todas as classes menos favorecidas.

Em outro momento, a personagem Eleanor fala que Friedrich Engels, amigo íntimo de seu pai, frequentador assíduo de sua casa e um dos mentores do Socialismo: "Tomou a dura decisão de voltar à empresa do familiar — onde ficou durante dezenove anos até que, depois da morte do pai, foi possível vender sua parte e dividir a renda com o Mouro. Só então pôde mudar para Londres e se dedicar, ele também, à militância revolucionária." (SILVEIRA, 2002, p. 79).

Ainda segundo a personagem,

Foi mais ou menos por essa época que Engels viu que a única maneira de garantir condições financeiras para que o Mouro (Marx) pudesse se dedicar a escrever sua obra teórica seria ele - nosso General - abdicar de suas ambições como jornalista e militante em Londres e assumir o emprego na firma do pai, em Manchester. Isso Ihe daria uma renda mais estável, parte da qual passou a enviar regularmente a nossa família (SILVEIRA, 2002, p. 28).

Eleanor revela para os leitores um lado de Engels que a História comumente não revela. A História fala de um Engels político, socialista, um homem forte, e ressalta principalmente os seus feitos. Eleanor apresenta o Engels humano, dedicado, amigo de Marx, a quem ele carinhosamente chama de Mouro. Um homem disposto a tudo para ajudar o amigo a alcançar seu ideal, inclusive de "abdicar de suas ambições como jornalista e militante", e de voltar a trabalhar com o pai para conseguir dinheiro e garantir condições financeiras para que Marx pudesse terminar seu trabalho. Por muito tempo, Engels enviou dinheiro à família de Marx para que este não tivesse que abandonar seus projetos. Observamos, então, que a obra ficcional tem esse caráter de sugerir, de revelar, 
de incitar, mas não de discutir. Ela nos permite outro olhar sobre o acontecimento histórico.

Observamos, também, na obra ficcional em estudo, esclarecimentos da personagem Eleanor com relação ao Socialismo, como a que se segue:

[...] nós não achamos que seja "ordem" um homem trabalhar dez, doze, catorze ou até mais horas por dia e, no final da vida, não ter nada de seu. Nós não achamos que seja "ordem" mulheres terem que se prostituir. Nós não achamos que seja "ordem" quando de um lado existem fábricas e depósitos abarrotados com superprodução e, de outro, milhares e milhares de pessoas que precisam desses mesmos artigos que apodrecem nas lojas. Tudo isso é desordem, e queremos acabar com isso e colocar uma ordem verdadeira no lugar (SILVEIRA, 2002, p. 72).

Neste recorte, Eleanor explica que os ideais socialistas postulam a igualdade social. Não reconhecem como justo um operário trabalhar muito mais que oito horas de serviço por dia e continuar vivendo miseravelmente. Não é justo, para os socialistas, que as fábricas produzam para exportação ou para acumularem estoque e que o povo que nelas trabalham passe fome. Esta não é a ordem, a ordem é a igualdade. Por este relato de Eleanor, percebemos como a História se imbrica na construção textual da obra em estudo, haja vista que as palavras de Eleanor, embora imbuídas de emoção, retratam realmente os ideais socialistas veiculados historicamente. Essas postulações apontam para o inquestionável viés romântico que perpassa o pensamento marxista.

Quando Eleanor fala sobre a desigualdade, a discriminação, os movimentos grevistas dos operários, toma posição diante dos fatos. Ela se posiciona, questiona e denuncia, como se percebe nos dois enunciados a seguir:

Na Inglaterra, começa a greve dos trabalhadores de gás, que se espalha como onda pelo setor industrial de Londres. Greves quase sempre são assim, contagiosas, podem virar epidemia. Quando trabalhadores de uma fábrica resolvem lutar por seus direitos, esse exemplo se torna quase irresistível porque por toda parte a situação é exatamente a mesma: salários miseráveis e terríveis condições de trabalho, como a longa jornada de trabalho, de dez a doze horas naquele momento (SILVEIRA, 2002, p. 103).

[...] os trabalhadores das ferrovias estão entre os que trabalham mais duro e recebem os piores salários (SILVEIRA, 2002, p. 106). 
Dentre os relatos contidos na obra em estudo um apresenta o efeito da condenação dos Oito de Chicago, em 1886. Eles foram acusados de explodirem uma bomba nas passeatas de maio pela redução da jornada de trabalho para oito horas, em que foi morto um policial. O julgamento, que foi qualificado pela obra como

[...] um dos mais venais da história - fora realizado precipitadamente, condenando, sem provas, sete deles à pena de morte, [...]. Eleanor, em seus discursos, denunciava uma condenação que se dera "não pelos fatos dos quais eram inocentes nem pela cor de suas opiniões políticas, mas simples e unicamente por que são trabalhadores e se opõem ao atual sistema" (SILVEIRA, 2002, p. 68).

O evento ocorreu em Chicago, uma região com um alto índice de industrialização e, por consequencia, com elevado número de operários. Podemos observar que a obra esclarece adequadamente sobre os acontecimentos factuais daquele momento, entretanto, verifica-se que há uma defesa desvelada dos acusados, há, portanto, a emissão de opiniões, uma tomada de posição da personagem, que acaba conduzindo o leitor a também construir sua opinião a respeito dos acontecimentos. Comentários como: "um dos julgamentos mais venais da história, julgamento realizado precipitadamente, condenação sem provas, condenação que se deu não pela inscrição política dos acusados, mas porque os mesmos são trabalhadores e lutam contra o sistema opressor" demonstram o que se disse a respeito do efeito da história sobre a alma do personagem.

Eleanor teve um amor proibido, Lissagaray, pois sua família não aprovava o relacionamento. Mesmo assim, ela ficou noiva dele por muitos anos.

[...] pensa constantemente em Lissagaray e começa a acreditar que o tempo será seu grande aliado para convencer o pai. Está decidida: não vai mais se contrapor diretamente ao Mouro para não zangá-lo ou preocupálo, mas tampouco abandonará seu noivo. Não pedirá mais para que recebam Lissa em casa e, por enquanto, se encontrará com ele sem que ninguém saiba (SILVEIRA, 2002, p. 63).

Verifica-se pela sucessividade dos trechos citados que o fato histórico se confunde com a vida aqui representada pelo drama pessoal da personagem. Com o tempo o noivado ficou desgastado, "O tempo está passando, sua juventude está passando, seu amor está passando, tudo está passando e ela não tem nada de seu para se agarrar" (SILVEIRA, 2002, p. 131). O desgaste do noivado ressignifica, neste contexto, a ferrugem que corrói a história. Ainda dividida entre o amor e a família, não conseguia dormir, nem 
comer, então, decidiu terminar o noivado e mergulhar no trabalho. Um tempo depois, contraiu matrimônio com Edward Aveling, outra personalidade conhecida da História que migrou para a obra. Edward, mesmo vivendo com Eleanor, casou-se clandestinamente em outra cidade com uma jovem. Ele era um homem cheio de segredos, ausentava-se de casa constantemente, não era carinhoso, tratava-a com indiferença e rejeição: "Tenho quase certeza de que Edward vai me abandonar. Sinto isso e seria uma completa idiota se não sentisse. A maneira como ele me trata, com tal indiferença, tal gelo, tal crueldade" (SILVEIRA, 2002, p. 143).

Após anos em um casamento infeliz, sentindo-se sozinha, não se alimentando nem dormindo direito, sem forças para lutar, ignorada pelo marido, Eleanor recebe uma carta contando do casamento clandestino dele. Ela pensa no suicídio. Planeja calmamente como irá proceder, escreve duas cartas, uma para Edward e outra para o sobrinho Johnny. Veste sua camisola branca, desfaz o coque e toma ácido prússico, conhecido como cianureto, veneno de efeito terrível. O modo como Eleanor se matou é descrito pela História, contudo, o que a levou a isso, suas angústias, o que pensava, o que sentiu nos momentos finais de sua vida, não é contemplado pela História. Nesse ponto, temos a obra literária, que pode, por meio da fiç̧ão, explicar o que Eleanor sentiu e descrever seus últimos momentos.

Por meio da história de amor vivida pela personagem, Maria José Silveira possibilita aos leitores outra interpretação da sociedade da época, dos costumes, das lutas sociais, da implantação do marxismo e da vida dessa pessoa real.

No epílogo do livro, a autora novamente recorre à História para se embasar e contar como foi o funeral de Eleanor Marx, como seu suicídio causou perplexidade no povo, pois se tratava de uma pessoa muito querida. O corpo foi cremado e suas cinzas se encontram, ainda hoje, em Londres, no mesmo túmulo de Karl Marx.

Entendemos que a História tradicional deu suas interpretações objetivas sobre a vida de Eleanor Marx, enquanto Maria José Silveira procurou mostrar, de forma romanceada, uma das possibilidades de como poderia ter sido essa vida.

Enfim, ressaltamos o papel da obra literária e da releitura da História a partir da Literatura como fundamental para a compreensão dos discursos políticos a respeito do Socialismo. Discursos esses que revelam o compromisso de um grupo de pessoas que lutou pelos direitos sociais e políticos dos cidadãos e por melhores condições de vida para 
todas as pessoas. Nesse sentido, entendemos que a obra literária traz a lume assuntos que, por razões diversas, são silenciados por aqueles que detêm o poder.

Além de revelar a importância da figura de Eleanor Marx no contexto do Socialismo inglês, a obra em estudo abre um espaço para que o leitor/interlocutor reflita sobre as verdades difundidas pelo governo, pelos meios de comunicação e por aqueles que ocupam cargos de comando e de direção. Ela instiga o leitor a questionar sobre as relações de poder estabelecidas socialmente e a participar de forma menos submissa nessas relações de poder.

\section{Considerações Finais}

Eleanor Marx, filha de Karl; um romance não é um documento histórico que relata fatos verídicos, mas uma obra literária ficcional que traz imbuídos em sua trama textual aspectos da vida de Eleanor Marx, da realidade social, política e histórica da sociedade inglesa do século XIX e da elaboração das ideias socialistas por Marx e Engels. Nesse sentido, a obra, além de nos proporcionar uma leitura agradável e intrigante, também nos revela conhecimentos acerca daquele contexto histórico e político e de algumas personalidades daquele período.

A autora articula ficção e História, utilizando personagens reais, como Eleanor, Marx, Engels, Edward Aveling, Liebknecht, entre outros, e acontecimentos históricos marcantes na época, no intuito de reconstruir essas personagens na ficção, aproximando-as da realidade, sem a intenção de retratá-los fielmente, já que este não é o objeto de uma obra literária.

Há, portanto, um diálogo muito intenso entre História, realidade e ficção na obra em análise. Em alguns pontos, chegam a se confundir e somos induzidos a pensar se muitos daqueles acontecimentos, daqueles pensamentos de Eleanor, foram reais ou não. E é isso que faz com que sintamos prazer ao ler a obra, pois Eleanor foi uma pessoa real, marcada pelo amor, pela luta, pelos ideais, pela reflexão, pela angústia. Enfim, foi uma pessoa que viveu em uma sociedade desigual e preconceituosa.

\section{Referências}


ALBUQUERQUE JÚNIOR, D. M. História, a arte de inventar o passado. Natal: 2006.

BAKHTIN, M. Questões de literatura e de estética. A teoria do romance. São Paulo: Hucitec, 1998.

BARTHES, R. Aula. Aula inaugural da cadeira de Semiologia Literária do Colégio de França. Pronunciada dia 7 de janeiro de 1977. Tradução: Leila Perrone-Moisés. São Paulo: Cultrix, 1989.

BORGES, V. R. História e literatura: uma relação de troca e cumplicidade. In: Revista História e Perspectivas, n. 9, UFU, 1993. Uberlândia.

CANDIDO, Antonio. Literatura e Sociedade: Estudos da Teoria e história Literária. 10 ed. Rio de Janeiro: Ouro sobre Azul, 2008.

CANDIDO, A. et al. A personagem de fiç̧ão. São Paulo: Perspectivas, 2007 (Coleção debates).

CARDOSO, J. B. Um mapa da História sobre o mapa da ficção. Goiânia: Editora da UCG, 2009.

COUTINHO, A. Introdução à Literatura no Brasil. 19 ed. Rio de Janeiro: Bertrand Brasil, 2007.

HUTCHEON, L. Poética do pós-modernismo: história, teoria e ficção. Rio de Janeiro: Imago, 1991.

KONSTANTINOV, F. et al. Fundamentos de filosofia marxista-leninista. Moscou: Progreso. 1982.

SANTOS, P. B. Teorias do romance: relações entre ficção e história. Santa Maria: Ed. da UFSM, 1996.

SILVEIRA, M. J. Eleanor Marx, filha de Karl, um romance. São Paulo: Francis, 2002.

WHITE, Hayden. Meta-história: a imaginação histórica do século XIX. Trad. de José Laurênio de melo. 2.ed. São Paulo, Edusp, 1995.

ZINANI, C. J. A. História da literatura: questões contemporâneas. Caxias do Sul: Educs (Editora da Universidade de Caxias do Sul), 2010. 